\title{
Chinweizu, I. (1990). AnATomy of female POWER: A MASCULINIST DISSECTION OF matriarchy. Lagos, Nigéria: Pero Press
}

\author{
Sara Maia
}

Chinweizu (nascido Chinweizu Ibekwe) é um crítico, poeta e jornalista nigeriano. A sua educação iniciou-se na Government Secondary School (em Afikpo, Nigéria), e posteriormente passou pelos Estados Unidos da América, no Massachusetts Institute of Technology (MIT) e na SUNY (em Buffalo). Enquanto estudou nos E.U.A. teve influência do movimento filosófico e artístico negro, e continua ainda a ser associado ao orientalismo negro. Os seus livros, ensaios e artigos de imprensa têm sido publicados em África, na Europa e na América do Norte. Alguns exemplos das suas obras mais populares e controversas são: The West and the Rest of Us: White Predators, Black Slavers, and the African Elite (1975), Toward the Decolonization of African Literature (1983) e Anatomy of Female Power: A Masculinist Dissection of Matriarchy (1990).

A obra Anatomia do poder feminino: uma dissecção masculinista do matriarcado (1990) de Chinweizu abre - logo na capa - com uma declaração que deixa bem claro o intuito da obra: "para todos os homens que têm sido confundidos, usurpados e abusados por mulheres, particularmente desde a chegada do Feminismo; e definitivamente não para mulheres". Já no interior, esta obra apresenta-se como um desafio ao Feminismo, anunciando que as mulheres sempre governaram os homens e que este é o momento de facultar ao masculino as ferramentas necessárias para subverter esta realidade, de forma a caminhar no sentido da igualdade de género.

Para levar a bom porto o seu objetivo, o autor estrutura o seu pensamento em três partes que são precedidas por uma epígrafe intitulada "Quem governa quem - homem ou mulher?", onde Chinweizu declara que a teoria do empoderamento masculino que circula na sociedade não passa de uma estratégia de propaganda bem edificada pelo Feminismo e naturalmente aceite, tanto por homens como por mulheres. Contudo, na opinião do autor são as mulheres que dominam os homens, sendo necessário examinar o poder feminino e a forma como ele opera socialmente. Deste modo, a obra começa por apresentar as características e pilares do poder feminino (parte I), para depois desenvolver as teorias daquilo que o autor chamou de "poder da mãe" (parte II), "poder da namorada" (parte III) e "poder da esposa" (parte IV), e para encerrar com uma parte dedicada ao matriarcado e aos seus descontentamentos (parte V).

Olhando para a estrutura da obra e para os objetivos que motivam o autor, é possível identificar, dentro do âmbito teórico dos Estudos Culturais, dois grandes pilares epistemológicos que se entrecruzam e comunicam: discursos de poder e relações de género. De facto, o autor procurar introduzir uma noção de poder (e a sua posição entre os 
géneros) que, por ser diferente e completamente descontextualizada no entendimento dos Estudos Culturais, merece que seja radiografada criticamente, para que os leitores da obra (particularmente os homens) não se deixem iludir por uma realidade que mostra uma opinião que, atacando as mulheres, pretende subverter a possibilidade de uma resistência feminina. Obviamente que o propósito desta recensão crítica não é dissecar por completo a obra, mas apresentar uma leitura global que permita uma interpretação crítica dos principais fundamentos apresentados pelo autor.

O problema do autor reside, logo à partida, na sua definição de poder como "posse" e não como "exercício": "se a essência do poder é a habilidade de conseguir o que queremos, então as mulheres estão longe de ser impotentes" (Chinweizu, 1990, p.11). Efetivamente, esta definição afasta-se da conceção foucaultiana de poder distribuído e envolvido nas relações do tecido social, o que, automaticamente, se revela desatualizado no contexto teórico pós-moderno. O poder não é o que queremos ou possuímos, mas sim o que é exercido e circula no feixe de relações organizadas, piramidal e coordenadamente (Foucault, 2010). Chinweizu, apontando críticas às atuações dos movimentos feministas, afirma que se o poder feminino existisse seria algo possuído pelas mulheres através da autoridade pública, criando aquilo que se conhece como "matriarcado". Contudo, para o autor, apesar de uma sociedade totalmente matriarcal não existir, isso não implica que não exista poder feminino, dizendo mesmo que ele é real e que se trata de uma espécie de "poder sem autoridade".

Embora Chinweizu reconheça que as mulheres não se encontram bem representadas nas estruturas públicas e institucionais, ele assume que existem muitas outras fontes de poder (educação, propaganda, castigo, reconhecimento, etc.) que estas possuem. Quer isto dizer que na sociedade há espaço para ambos os géneros e que apesar de, aparentemente, as sociedades parecerem falocêntricas e patriarcais existe, nos bastidores, uma versão feminina das mesmas. Trata-se de uma hierarquia pouco clara das relações de poder entre homens e mulheres:

porque cada homem tem como chefe a sua própria esposa, ou a sua mãe, ou qualquer outra mulher na sua vida, os homens podem governar o mundo, mas as mulheres governam os homens que governam o mundo (Chinweizu, 1990, p. 12).

Chinweizu assegura, portanto, que o poder feminino existe sobre o masculino e que se manifesta através de cinco pilares principais: 1) o controlo feminino sobre o ventre; 2) o controlo feminino sobre a cozinha; 3) o controlo feminino sobre o berço; 4) a imaturidade psicológica dos homens em relação às mulheres; e 5) a tendência do homem a ser perturbado pela excitação física. Destes pilares, o autor destaca o poder do ventre feminino, pois a mulher possui a excecionalidade de dar à luz. Chinweizu mostra ainda que estes cinco pilares podem ser condensados em apenas três fases: o "poder da mãe", o "poder da namorada" e o "poder da esposa" (já supracitados). Chinweizu encontra ainda espaço para caracterizar ambos os géneros, atribuindo força, confronto, agressividade e comando ao masculino, e calma, passividade, emoção e capacidade de 
manipulação ao feminino. Estas atribuições não passam de imagens estereotipadas que são reproduzidas na sociedade (que este autor facilmente vulgariza) e que dão visibilidade ao poder masculino e atribuem inferioridade ao poder feminino. Todavia, Chinweizu afirma que estas características femininas são propositadamente utilizadas para enganar os homens, para, de forma simulada e inteligente, governá-los.

Para o autor, esta espécie de "matriarcado escondido" é uma opção consciente das mulheres, pois estas preferem não ter de lidar com as obrigações a que a exposição do seu poder thes poderia trazer. As mulheres preferem posições com pouca pressão e baixo risco, liderando por trás do trono do patriarcado: "sob este acordo, uma mulher tem tudo a ganhar e nada a perder, exceto pequenas vaidades" (Chinweizu, 1990, p. 75). Aos olhos de Chinweizu, e subvertendo a teoria foucaultiana (Foucault, 2006; 2010), poder-se-ia entender (pretensiosamente) esta posição das mulheres como o "poder de resistência" ao poder masculino, embora esta seja uma possibilidade que Judith Butler (2006) e Pierre Bourdieu (1990) entendem como difícil, na medida em que a sociedade está submetida a estruturas de ordem masculina. É no seio desta discussão que Chinweizu coloca uma questão: porque é que os homens não se revoltam com esta situação e impõem um verdadeiro patriarcado? Para ele, a resposta é simples: porque esta é uma fachada que alimenta o ego masculino o suficiente, e, para além disso, as mulheres não o iriam permitir.

Ao contrário do que muitos teóricos (modernos, pós-modernos, estruturalistas, pós-estruturalistas, feministas e pós-feministas) defendem, Chinweizu afirma que o poder feminino existe e opera sobretudo no casamento', mas não em larga escala institucional, porque não há essa necessidade: “o poder feminino não precisa dessas estruturas elaboradas de autoridade formal que evoluíram para controlar os grandes agregados de pessoas exigidas pelas atividades especializadas do domínio masculino" (Chinweizu, 1990, p.111). A teoria de Chinweizu (1990) mostra-se assim antifeminista e atrevida, ao tentar afastar-se da tradicional conceção da submissão "incontrolável" do sexo feminino ao masculino. Contudo, é importante fazer-se outra leitura desta teoria, pois, apesar do autor destacar constantemente que a posição de "poder por trás do trono" é uma posição consciente das mulheres, esta pode ser apenas a única forma de "poder" que lhes é consentida.

Embora o discurso do autor ambicione, por vezes, caminhar no sentido da libertação das mulheres (evidenciada na consciência da sua própria condição), frequentemente as suas palavras acentuam o conformismo e não preveem a capacidade das mulheres irem mais além nos seus modelos de resistência ao poder masculino. No âmbito de algumas teorias feministas, esta pode revelar-se como uma das formas machistas de dar um falso sentido de liberdade e de poder às mulheres. Chinweizu apenas parece dar continuidade ao simbolismo lacaniano (Lacan, 1981) que sedimenta práticas sociais que perpetuam a heteronormatividade cultural através da estrutura familiar edipiana (falocêntrica). Esta visão afasta-se totalmente da pós-estruturalista, que repensa toda a estrutura social de poder com base num queerismo da psique, da diferença sexual e do género.

\footnotetext{
' O casamento e o controlo da família são uma espécie de "organização do ninho".
} 


\section{REFERÊNCIAS}

Bourdieu, P. (1999). A dominação masculina. Oeiras: Celta Editora.

Butler, J. (2004). Undoing gender. Col. Gender studies, Philosophy. Nova lorque: Routledge.

Foucault, M. (2006). Estratégia, poder-saber. Organização de Manoel Motta. Rio de Janeiro: Editora Forense Universitária. $2^{\mathrm{a}}$ ed.

Foucault, M. (2010). Microfisica do poder. Com organização, introdução e revisão técnica de Roberto Machado. São Paulo: Graal.

Lacan, J. (1981). The language of the self: the functions of language in psychoanalysis. Traduzido, com notas e comentários de Anthony Wilden. Baltimore: The Johns Hopkins University Press.

Sara Vidal Maia Doutoranda em Estudos Culturais, Universidade de Aveiro/Universidade do Minho; Mestre em Gestão e Planeamento em Turismo pelo Departamento de Economia, Gestão e Engenharia Industrial da Universidade de Aveiro; Licenciada em História da Arte pela Faculdade de Letras da Universdade de Coimbra; Bolseira de doutoramento pela Fundação para a Ciência e a Tecnologia (FCT) no domínio das Ciências da Comunicação e Informação; Investigadora do Centro de Estudos de Comunicação e Sociedade da Universidade do Minho; Presidente da Assembleia da Associação IRENNE - Associação de Investigação, Prevenção e Combate à Violência e Exclusão; Membro do GT Género e Sexualidades da SOPCOM.

E-mail: saravmaia@ua.pt

Universidade de Aveiro / Universidade do Minho Instituto de Ciências Sociais, Campus de Gualtar 4710-057 Braga Portugal

* Submetido: 16-02-2015

* Aceite: 20-04-2015 